\title{
BIOLOGICAL AND ECOLOGICAL TRAITS THAT ASSIST ESTABLISHMENT OF ALIEN INVASIVE INSECTS
}

\author{
L. PEACOCK ${ }^{1}$ and S.P. WORNER ${ }^{2}$
}

\author{
${ }^{I}$ MAF Biosecurity New Zealand, PO Box 2526, Wellington, New Zealand \\ ${ }^{2}$ Bio-Protection and Ecology Division, Lincoln University, PO Box 84, \\ Canterbury, New Zealand
}

Corresponding author:Lora.Peacock@maf.govt.nz

\begin{abstract}
In this study the biological and ecological traits of two groups of phytophagous insect pests were examined to determine attributes that may influence establishment in New Zealand. Biological and ecological attributes of a group of insect species that is established in New Zealand were compared with species that are not currently established. It was found that the species established in New Zealand had a significantly wider host plant range than species that have not established. The lower developmental threshold temperature was, on average, $4^{\circ} \mathrm{C}$ lower for established species compared with non-established species. These data suggest that species that establish well in New Zealand have a wide host range and can tolerate lower temperatures compared with those that have not established.
\end{abstract}

Keywords: biological invasions, biological traits, establishment success, phytophagous insect pests, temperate climate.

\section{INTRODUCTION}

It is well recognised that there are biological and physiological characteristics that make some species more invasive than others. Despite many studies of such characteristics, there is no consensus about which may be most significant for insect establishment success. Studies in insects suggest that a high reproductive capacity at low population levels can often ensure long-term population persistence after initial establishment. For example, in their study of the invasion of North American forests by European phytophagous insects, Niemela \& Mattson (1996) report that invasion success could be attributed to parthenogenesis. Parthenogenesis in insects allows them to quickly exploit new resources while avoiding the constraints of mate finding (Lattin \& Oman 1983; Ehrlich 1986) and clearly this life history strategy would be a useful characteristic for an invasive species. Polyploidy and pseudosexual reproduction (apomixes) are often associated with the parthenogenetic process, adding genetic diversity and enabling an insect to survive very broad ecological and environmental ranges (Niemela \& Mattson 1996). The ability to survive a wide range of environmental conditions is clearly a key factor for the success of insect establishment and invasiveness.

The availability of resources or host plants is essential for insect establishment. According to Lattin \& Oman (1983) the successful colonisation of many insect species into North America from Europe is related to the large ecological resources available. For the survival of phytophagous insect species in a new location the abundance and biological and ecological similarity of potential host plants to the invasive species native host plant range is very important (Simberloff 1989). And according to Simberloff (1989), successful insect invasion from Europe into North America has been attributed to the taxonomic similarity between North American plant species and European plant species.

Another factor that can determine whether colonisation will be successful is the number of individuals colonising or invading the new area (propagule pressure). It is thought 
that the higher the propagule pressure the greater the chance of successful establishment (Williamson 1996; Williamson \& Fitter 1996; Duncan et al. 2001, 2003). The level of propagule pressure required for successful establishment may vary from species to species (Berggren 2001), but in insects there have been few studies that have experimentally tested the influence of propagule pressure on establishment success (Grevstad 1999; Memmott et al. 1998; Berggren 2001).

Insect body size may also influence invasion success. It is thought that populations of smaller-bodied organisms are more likely to be successful invaders as they have higher rates of intrinsic growth and can establish quickly (Moulton \& Pimm 1986; Gaston \& Lawton 1988; Williamson \& Fitter 1996; Forys \& Allan 1999). In a study of biological control programmes for the control of weedy species, Crawley (1987) found that small bodied insect species were more likely to establish successfully. However, in that study the number of insect species that had successfully established was relatively small.

There have been attempts to link taxonomic status of species to successful establishment or invasion success. However, it is difficult to isolate the importance of taxonomic status from other confounding factors, such as dispersal mechanisms or human assisted pathways that influence arrival and establishment at new locations. During a ten year period (1990-1999) Mack et al. (2002) found that of all species intercepted on imported propagation plant material at United States ports, approximately $30 \%$ of all arthropods were Homoptera, 9.2\% were Lepidoptera and Thysanoptera accounted for $3.2 \%$. They concluded that insect species arrivals simply reflected the types of species that are more likely to be associated with the plant material that is imported. A study by Sailer (1978) illustrates these observations particularly well by relating the different proportions of insect species belonging to major taxonomic orders arriving into the United States with changes in trade and transport. For example, in 1820 high numbers species of Coleoptera arrived because at that time soil was commonly used as ship ballast. Eventually, the invention of the steam ship resulted in fast, more efficient trade in plant produce, thus increasing the proportion of Homoptera species establishing (Sailer 1983).

To refine our knowledge and to adequately test hypotheses concerning theoretical and applied aspects of invasion biology, successful and unsuccessful invaders should be compared (Worner 2002). The aim of this study was to determine insect establishment patterns by comparing biological attributes of two groups of phytophagous insect species that are continually intercepted at New Zealand's border. One group of species is established in New Zealand, while the other group comprised species that are not established. For the purpose of the present study the two groups were considered to respectively represent successful and unsuccessful invaders.

\section{METHODS}

A list of all phytophagous insect species intercepted from 1993 to 1999 at the New Zealand border was compiled from interception data $(n=132)$ held by the Ministry of Agriculture and Forestry, New Zealand. From this list, two groups of insect species were randomly selected for further study. The subset of species was selected using random number tables generated using Minitab ${ }^{\mathrm{TM}}$ Version 13.1. One group consisted of 15 insect species that had established in New Zealand but were still intercepted (successful invaders). The second group comprised 21 species that had not established but were also intercepted over the 7-year period (unsuccessful invaders). Published sources and personal communication were used to verify that the established group of insect species had indeed established in New Zealand (Cottier 1953; Mound \& Walker 1982; Cox 1987; Dugdale 1988; Scott \& Emberson 1999; Hodgson \& Henderson 2000; Charles \& Henderson 2002; and personal communications from R.C. Henderson, Landcare Research; R.J.B. Hoare, Landcare Research; J.W.M. Marris, Lincoln University; D.A.J. Teulon, Crop \& Food Research). The variables hypothesised to be different between the two groups were host range, developmental temperature thresholds, propagule pressure (the number of individuals arriving into the country), body size and taxonomic status. These variables were quantified for each species by literature search. The data collected from literature searches were first tested for normality using Minitab ${ }^{\mathrm{TM}}$ (Version 13.1). 
T-tests were then carried out and $95 \%$ confidence intervals calculated to determine if there were significant differences between the characteristics of the two groups of successful and unsuccessful and invaders.

\section{Host plant range}

\section{RESULTS}

The average number of plant hosts per species was found to be significantly different between the two groups of insects. The insect species that have established in New Zealand had a wider host range $(34.5 \pm 9.8)$ than the non-established species $(18.4 \pm$ 4.9) $(\mathrm{P}=0.002)$. Similarly, the average number of plant families that are hosts for the two groups was significantly different $(\mathrm{P}=0.021)$, with the New Zealand established species appearing to utilise more varieties of plant families $(16.7 \pm 4.8)$ than the non established species $(9.9 \pm 3.3)$.

\section{Developmental requirements}

Established species had, on average, a lower developmental threshold $\left(7.4 \pm 1.56^{\circ} \mathrm{C}\right)$ and shorter development time $(238.9 \pm 135.4$ degree days $)$ compared with the non-established species (threshold of $11.3 \pm 2.0^{\circ} \mathrm{C}$ and developmental time of $393.5 \pm 202.1$ degree days). While the difference in mean lower developmental threshold was statistically significant $(\mathrm{P}=0.003)$, the difference between mean development times $(\mathrm{P}=0.138)$ was not. The data for development times were highly variable and therefore a larger sample size would be required to detect if a significant difference exists.

\section{Propagule pressure and body size}

If it is assumed that the border interception rate for a species is an index of propagule pressure or indicates the number of opportunities to establish, it appears that there is no difference $(\mathrm{P}=0.982)$ in the annual average arrival rate of non-established species $(2.34 \pm 1.94$ interceptions per species) compared with established species $(2.32 \pm 1.37$ interceptions per species per year).

Species that had not established, where body length measurements were available $(n=12)$, had an average body length of $4.18 \pm 2.99 \mathrm{~mm}$, slightly larger than the body length of the non established species $(\mathrm{n}=13)(2.72 \pm 1.10 \mathrm{~mm})$. The variation in body size across both groups was such $(3-19 \mathrm{~mm})$ that differences between the groups were not statistically significant $(\mathrm{P}=0.583)$.

\section{Taxonomic differences}

Figure 1 shows that the highest interception rates in New Zealand are among insect species belonging to the families Diaspidae (Homoptera), Pseudococcidae (Homoptera) and Pyralidae (Lepidoptera). It appears that many species of the family Aphididae (Homoptera) are very successful at establishing in New Zealand compared with other insect families.

\section{DISCUSSION}

It is well known that the distribution of insect species is related to the abundance and geographic range of their plant hosts (Niemela \& Mattson 1996). Because they have a wide host range the established exotic species investigated in this study are more likely to find a host in their non-native range. Additionally, a wide variety of plant species is available in New Zealand through diverse horticultural and agricultural production made possible because of a wide variety of micro-climates. For example, tropical fruits can be grown in Northern New Zealand while temperate varieties are grown elsewhere. However, while the non-established insect species may have reduced probability of establishment because they have a narrower host range, that does not fully explain nonestablishment, which is clearly influenced by multiple factors. Some subtropical species that have not established in New Zealand, for example, the scales, Aspidiotus destructor and Pseudaulacaspis pentagona, and the thrips species, Thrips palmi, have a wide host range (Peacock 2005). One explanation for non-establishment of these species is that their climatic requirements are not met. 


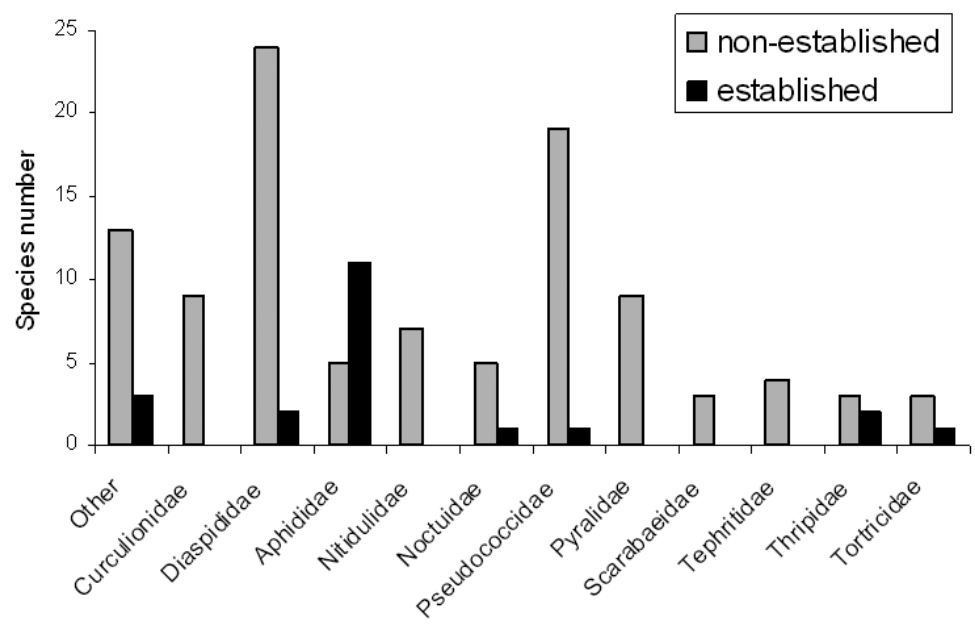

FIGURE 1: The number of species intercepted in each insect Family (1993-1999,
$\mathbf{n = 1 3 2}$ ).

This study found a significant difference in average lower developmental threshold between the two groups of study insects despite the small sample size. The confidence intervals around the mean developmental threshold for both the established and nonestablished species could provide an important risk criteria for formal risk assessments of species considered to threaten New Zealand's biological industries or its environment. While the sample sizes for each group in this study was small, other studies such as Worner \& Gevrey (2006) and Gevrey et al. (2006) could add more species to each group giving greater power to detect differences if they exist. While it is clear that detailed information for more species is needed, it is unfortunate that much needed development data is lacking for many potential invasive species.

Despite many studies the influence of propagule pressure on insect establishment remains unclear. Berggren (2001) showed that large propagule sizes of Roesel's bush cricket, Metrioptera roeseli, were more successful at colonising new habitat islands within farmland fields in South East Sweden than small propagule sizes. Similarly, Grevstad (1999) found that the probability of establishment increased with release size of two plant feeding chrysomelid beetles, Galerucella calmariensis and G.pusilla, introduced as biocontrol agents for purple loosestrife, Lythrum salicaria, in New York. However, there are many exceptions to such findings where very small populations have been shown to establish successfully. For example, in Hawaii, the release of just 11 individuals of the biocontrol agent chalcidid endoparasitoid, Brachymeria agonoxena, resulted in the successful establishment of this species (Simberloff 1989). In New Zealand the parasitoid Aphelinus mali, established from just five individuals (Shaw \& Walker 1996). Similarly, Memmott et al. (1998) found that the release of a number of small populations $(<100$ individuals) of the biocontrol agent, Sericothrips staphylinus (gorse thrips), was more likely to result in successful establishment than a single release of a large population (>1000 individuals). A later study showed that the psyllid Arytainilla spartiophila could establish successfully with just a couple of individuals from initial release (Memmott et al. 2005). In our study, there was no difference in propagule pressure between successful and unsuccessful insect species. It appears therefore that the role of propagule pressure in successful establishment remains unclear or that chance combinations of multiple factors for species that are pre-disposed to establishment will result in colonisation. More studies need to be carried out to further investigate the role of propagule pressure. 
In general, insect species with higher rates of population increase are thought to have a higher probability of establishment (Crawley 1987; Gaston \& Lawton 1988), and typically species that have high rates of intrinsic population growth tend to be small bodied. But small bodied species are susceptible to rapid environmental changes resulting in high variability in population size. Gaston \& Lawton (1988) studied the influence of insect body size on the distribution and abundance of species across taxonomic orders. While they found a negative relationship between body size and distribution, they concluded that the effect of body size on population abundance and distribution was inconsistent between taxonomic groups. They concluded that their data only weakly supported the theory that small bodied organisms had an increased probability of establishment and survival when introduced to a new locality. Similarly, in the present study there was no indication that smaller bodied insect species were more likely to establish in New Zealand than larger bodied ones.

Of all the families intercepted, members of Aphididae were the most successful at establishing in New Zealand. Many aphid species are cosmopolitan and distributed widely in temperate regions, particularly in the Northern Hemisphere where they are adapted to climates with quite cool winters with many species laying diapause eggs in autumn. According to Heie (1994), 85\% of the genera in Aphididae are endemic to the Northern Hemisphere with only $0.4 \%$ endemic to the Southern Hemisphere temperate regions. If aphids from the Northern Hemisphere were to colonise areas on the other side of the world they would need to quickly produce at the right time so that viable eggs could hatch in the Southern Hemisphere spring. Thus the mode and timing of arrival are very important for such species. This is especially true for the egg stage for some species where that stage is highly suitable for colonisation. The eggs of aphids often have long periods of dormancy, particularly over the winter period. Teulon \& Stufkens (2002) examined historical records and showed that once aphid species arrive in New Zealand, they tend to establish and spread rapidly and become very difficult to eradicate. A good example is the blue-green lucerne aphid, Acyrthosiphon kondoi, which took less than a year to spread throughout New Zealand.

In conclusion, host plant range and insect development threshold have been shown to be important factors for establishment success of exotic phytophagous insects in New Zealand. The New Zealand established insect species investigated in this study tended to have a wider host plant range than insect species that have not established indicating a greater chance of survival in a novel location. The $4^{\circ} \mathrm{C}$ lower development threshold for established species indicates increased survival through winter cold and appears a key factor for successful establishment in temperate New Zealand. Confidence intervals for host range and developmental thresholds of invertebrate species, together with other traits found significant in other studies, have potential to provide quantitative information that can inform invasive insect risk assessments that are currently largely qualitative.

\section{ACKNOWLEDGEMENTS}

We thank Barney Stephenson from the New Zealand Ministry of Agriculture and Forestry, Wellington, for the use of the plant pest interception data and Lincoln University, Canterbury, for providing funding for this research.

\section{REFERENCES}

Berggren A 2001. Colonization success in Roesel's bush-cricket Metrioptera roeseli: the effects of propagule size. Ecology 82(1): 274-280.

Charles JG, Henderson RC 2002. Catalogue of the exotic armoured scale insects (Hemiptera: Coccoidea: Diaspididae) in New Zealand. Journal of the Royal Society of New Zealand 32(4): 587-615.

Cottier N 1953. Aphids of New Zealand. New Zealand D.S.I.R. Bulletin 106. 382 pp. 
Cox JM 1987. Pseudococcidae (Insecta: Hemiptera). Fauna of New Zealand 11. 230 pp. Crawley MJ 1987. What makes a community invasible? In: Gray AJ, Crawley MJ,Edwards PJ ed. 26th symposium of the British Ecological Society. Colonisation, Succession and Stability. Blackwell Scientific Publishers, London. Pp. 429-453.

Dugdale JS 1988. Lepidoptera- annotated catalogue and keys to family and group taxa. Fauna of New Zealand 14. 264 pp.

Duncan PR, Bomford M, Forsyth DM, Conibear L 2001. High predictability in introduction outcomes and the geographical range size of introduced Australian birds: a role for climate. Journal of Animal Ecology 70: 621-632.

Duncan RP, Blackburn TM, Sol D 2003. The ecology of bird introductions. Annual Review of Ecology and Evolution Systematics 34: 71-98.

Ehrlich, PR 1986. Which animal will invade? In: Mooney HA, Drake JA ed. Ecological series 58: Ecology of biological invasions of North America and Hawaii. SpringerVerlag, New York. Pp. 79-95.

Forys EA, Allen CR 1999. Biological invasions and deletions: community change in south Florida. Biological Conservation 87: 341-347.

Gaston KJ, Lawton J 1988. Patterns in the distribution and abundance of insect populations. Nature 331(February): 709-712.

Gevrey M, Worner SP, Kasabov N, Pitt J, Giraudel JL 2006. Estimating Risk of Events Using SOM Models: A Case Study on invasive species establishment. Ecological Modelling 197: 361-372.

Grevstad FS 1999. Experimental invasions using biological control introductions: the influence of release size on the chance of population establishment. Biological Invasions 1: 313-323.

Heie OE 1994. Why are there so few aphid species in the temperate areas of the southern hemisphere? European Journal of Entomology 91: 127-133.

Hodgson CJ, Henderson RC 2000. Coccidae (Insecta: Hemiptera: Coccoidea). Fauna of New Zealand No. 41. 264 pp.

Lattin JD, Oman P 1983. Where are the exotic insect threats? In: Wilson CL, Graham CL ed. Exotic plant pests and North American agriculture. Academic Press, New York. Pp. 93-137.

Mack RN, Barrett SCH, Defur PL, MacDonald WL, Madden LV, Marshall DS, McCullogh DG, McEvoy PB, Nyrop MP, Reichard SEH, Rice KJ, Tolin SA 2002. Predicting invasions of non-indigenous plants and plant pests. National Academy Press, Washington D.C. 194 pp.

Memmott J, Fowler SV, Hill RL 1998. The effect of release size on the probability of establishment of biological control agents: gorse thrips (Sericothrips staphylinus) released against gorse (Ulex europaeus). Biocontrol Science and Technology 8(1): 103-115.

Memmott J, Graze PG, Harman HM, Syrett P, Fowler, SV 2005. The effect of propagule size on the invasion of an alien insect. Journal of Animal Ecology 74: 50-62.

Moulton MP, Pimm SL 1986. Species Introductions to Hawaii. In: Mooney HA, Drake JA ed. Ecology of biological invasions of North America and Hawaii. SpringerVerlag, New York. Pp. 231-249.

Mound LA, Walker AK 1982. Terebrantia (Insecta: Thysanoptera). Fauna of New Zealand $1.113 \mathrm{pp}$.

Niemela P, Mattson WJ 1996. Invasion of North American Forests by European phytophagous insects. Bioscience 46(10): 741-753.

Peacock L 2005. Eco-climatic assessment of the potential establishment of exotic insects in New Zealand. PhD thesis, Lincoln University, Canterbury, New Zealand. $203 \mathrm{pp}$.

Rejmanek M 1995. What makes a species invasive? In: Pysek P, Prach K, Rejmanek $\mathrm{M}$ ed. Plant invasions general aspects and problems. Academic Publishing, Amsterdam Pp. 3-13. 
Rejmanek M, Richardson DM 1996. What attributes make some plant species more invasive. Ecology 77(6): 1666-1670.

Sailer RT 1978. Our immigrant fauna. Bulletin of the Entomological Society of America 24(1): 3-11.

Sailer RT 1983. History of Insect Introductions. In: Graham C, Wilson C ed. Exotic plant pests and North American Agriculture. Academic Press, New York. Pp. 15-38.

Scott RR, Emberson RM 1999. Handbook of New Zealand Insect Names, Common and Scientific Names for Allied Organisms. Entomological Society of New Zealand, Auckland, New Zealand. 100 pp.

Shaw PW, Walker JTS 1996. Biological control of woolly apple aphid by Aphelinus mali in an integrated fruit production programme in Nelson. Proceedings of the 49th New Zealand Plant Protection Conference. Pp. 59-63.

Simberloff D 1989. Which insect introductions succeed and which fail. In: Drake JA, Mooney HA, Di Castri F, Groves RH, Kruger FJ, Rejmanek M, Williamson M ed. Biological invasions: a global perspective. John Wiley \& Sons Ltd, New York. Pp. 61-75.

Teulon DAJ, Stufkens MAW 2002. Biosecurity and aphids in New Zealand. New Zealand Plant Protection 55: 12-17.

Williamson MH, Fitter A 1996. The characters of successful invaders. Biological Conservation 78: 163-170.

Williamson MH 1996. Biological Invasions. Chapman \& Hall, London. 244 pp.

Worner SP 2002. Predicting the invasive potential of exotic insects In: Halman G, Schwabe CP ed. Invasive arthropods and agriculture: problems and solutions. Science Publishers, Inc., Enfield, New Hampshire, USA. Pp. 119-137.

Worner SP, Gevrey M 2006. Modelling global insect species assemblages to determine risk of invasion. Journal of Applied Ecology 43: 858-867. 